\title{
Massive pleural effusion: an uncommon but important cause to consider
}

\author{
Avneet Garg®, Khushdeep Singla, Mansimranjit Kaur, Vinita Jindal, Manjot Kaur \\ Adesh Institute of Medical Sciences and Research, Bathinda, Punjab, India
}

A 44 years old female presented with complaints of diffuse right sided chest pain, progressively increasing shortness of breath (mMRC grade 3), fever, loss of weight and anorexia for last 2 months. She had history of dysphagia to solids, intermittent vomiting and regurgitation during feeding for which she was taking symptomatic treatment from local practitioner. Her vitals were heart rate $88 / \mathrm{min}$, blood pressure $116 / 78 \mathrm{mmHg}$, respiratory rate $21 / \mathrm{min}$ and saturation of $95 \%$ on room air. Chest examination showed findings suggestive of pleural effusion which was confirmed on chest X-ray. CECT chest was planned in view of massive right sided pleural effusion with air loculations on chest X ray. Oral contrast on table was administered in view of esophageal wall thickening on NCCT chest. CT-scan with oral contrast showed fistulous track from right lateral aspect of thoracic esophagus extending to right pleural cavity suggesting esophageal-pleural fistula (Figure 1). Upper GI endoscopy showed ulcerative proliferative growth in the thoracic esophagus with suspicious fistulous opening showing pus drainage. Biopsy revealed squamous cell carcinoma of esophagus. Intercostal tube drainage was done for right sided massive effusion which drained about 2.5 liters of purulent material. Pleural fluid examination showed amylase $-3141 \mathrm{U} / \mathrm{L}$, protein $-4.6 \mathrm{gm} / \mathrm{dL}$, sugar $-174 \mathrm{mg} / \mathrm{dl}$, LDH-120U/L and gram negative bacilli on gram staining. Feeding jejunostomy was performed and empirical broad spectrum antibiotics were started. Follow-up chest X-ray showed significantly reduced pleural effusion with partial lung expansion. Patient was transferred to department of gastrointestinal surgery for further definitive surgical management.

Esophageal-pleural fistula presenting as massive pleural effusion is rarely encountered. The diagnosis of EPF is difficult as symptoms and signs related to EPF are non-specific and can mimic many other diseases. Hence a meticulous history taking and high degree of clinical suspicion is must to diagnose EPF. History of
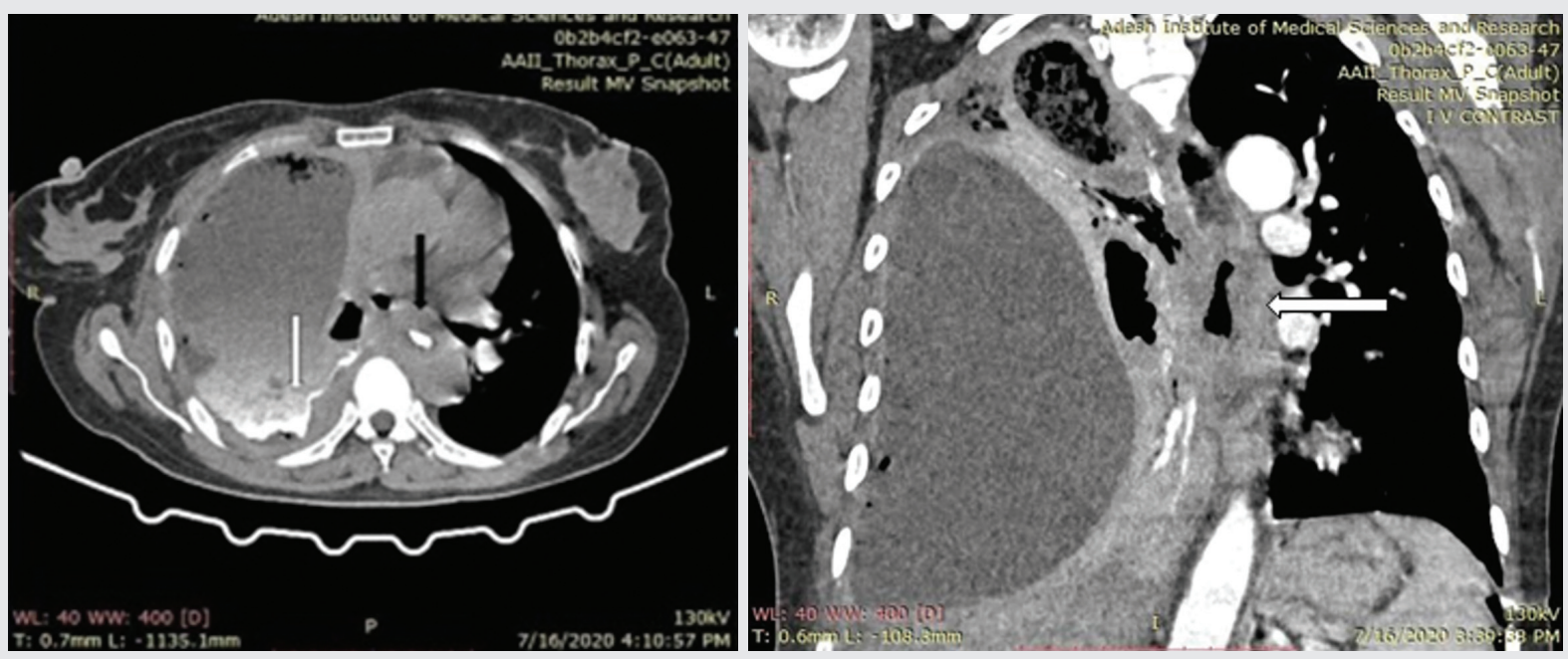

Figure 1. Axial and coronal CECT images show right sided hydro-pneumothorax. Oral contrast filled fistulous track seen from mid esophagus to right pleural cavity (shown as white arrow in axial CT). Circumferential eccentric wall thickening of esophagus is seen (shown as black arrow in axial CT and white arrow in coronal CT)

Address for correspondence: Avneet Garg, Adesh Institute of Medical Sciences and Research, Bathinda, Punjab, India, e-mail: dravneetgarg@gmail.com Conflict of interest: None declared.

D0I: 10.5603/ARM.a2021.0109 | Received: 03.06.2021 | Copyright (C) 2021 PTChP | ISSN 2451-4934 | e-ISSN 2543-6031

This article is available in open access under Creative Common Attribution-Non-Commercial-No Derivatives 4.0 International (CC BY-NC-ND 4.0) license, allowing to download articles and share them with others as long as they credit the authors and the publisher, but without permission to change them in any way or use them commercially. 
dysphagia, odynophagia, a known esophageal malignancy, esophageal ulcer or trauma and prior upper GI endoscopy or esophageal instrumentation can help to raise the clinical suspicion [1, 2]. Various imaging modalities that aid in diagnosis include chest radiograph, ultrasound, barium swallow, contrast-enhanced CT, and MRI with each modality having its own advantages; however CECT chest is very useful modality and should be performed early whenever there is clinical suspicion. CT chest can show focal esophageal wall thickening as in our case, thinning or ballooning of esophagus at the site of perforation, mediastinitis and can help to delineate the fistulous track after giving oral contrast which is the pathognomonic sign of esophageal - pleural fistula. CT chest can delineate pleural lesions from parenchymal and help to exclude other alternate differential diagnosis [3, 4]. Upper GI endoscopy helps to confirm the etiology of EPF and hence helps in the further definitive management for EPF. The management options include conservative therapy like empyema drainage, management of mediastinitis, tube feeding, feeding jejunostomy or gastrostomy; stenting or definitive surgical repair for EPF and endoscopic management like stenting, suturing, fibrin glue or clips. Early treatment helps to prevent further devastating complications [5]. EPF should be considered as one of differentials for unilateral massive pleural effusion.

\section{References:}

1. Pache G, Thuerl C, Bley T, et al. Asymptomatic esophago-pleural fistula presenting 35 years after pneumonectomy for tuberculosis. J Thorac Imaging. 2005; 20(3): 223-225, doi: 10.1097/01.rti.0000155043.74533.79, indexed in Pubmed: 16077339.

2. Vyas S, Prakash M, Kaman L, et al. Spontaneous esophageal-pleural fistula. Lung India. 2011; 28(4): 300-302, doi: 10.4103/09702113.85696, indexed in Pubmed: 22084548.

3. Dash M, Mohanty T, Patnaik J, et al. An unusual case of spontaneous esophagopleural fistula. Lung India. 2017; 34(3): 287-289, doi: 10.4103/0970-2113.205327, indexed in Pubmed: 28474659.

4. Chuah BYS, Khoo KL, Khor CJL. Clinical challenges and images in GI. Esophagopleural fistula. Gastroenterology. 2008; 134(4): 919, 1275, doi: 10.1053/i.gastro.2008.02.040, indexed in Pubmed: 18395073.

5. Vandenplas Y, Helven R, Derop H, et al. Endoscopic obliteration of recurrent tracheoesophageal fistula. Dig Dis Sci. 1993; 38(2): 374-377, doi: 10.1007/BF01307559, indexed in Pubmed: $\underline{8425452}$. 